\title{
FECUNDIDADE E SAÚDE REPRODUTIVA DAS MULHERES SUYÁ (KISÊDJÊ): aspectos demográficos e culturais ${ }^{1}$
}

\author{
Heloisa Pagliaro* \\ Sofia Mendonça $a^{* *}$ \\ Roberto Baruz:? i**
}

\begin{abstract}
Assim como vem ocorrendo com outros povos indígenas no Brasil, os Suyá, povo habitante do Parque Indígena do Xingu (MT), têm vivenciado, desde 1970, um processo de recuperação demográfica. Trabalhos recentes discutem as razões que levaram à reversão do longo processo de depopulação vivenciado pelos povos indígenas no Brasil. A suposição de que o processo de recuperação populacional dos Suyá tenha sido gerado por mudanças socioculturais, com repercussão no seu comportamento reprodutivo, estimulou a realização deste estudo, que descreve os seus níveis e padrões da fecundidade entre 1970 e 2007. As bases de dados são estatísticas vitais contínuas e levantamento de campo. A discussão dos resultados apoia-se em informações sobre o sistema sociocultural e os conhecimentos tradicionais de saúde reprodutiva desse povo indígena.
\end{abstract}

PaLAvras Chave: Suyá, demografia indígena, fecundidade de mulheres indígenas, povos indígenas no Brasil.

\section{INTRODUÇÃO}

$\mathrm{O}$ crescimento dos povos indígenas que habitam o território brasileiro, observado nas últimas três décadas (Gomes, 1991; Melatti, 2004; Azevedo, 2000), constitui um evento de grande

* Doutora em Saúde Publica. Pesquisadora do Projeto Xingu, da Universidade Federal de São Paulo. Bolsista de Produtividade de Pesquisa II do CNPq.

Rua Borges Lagoa, 1341. Vila Clementino. Cep:04038034

- Sao Paulo, SP - Brasil. pagliaro@unifesp.br

* * Doutoranda em Saúde Coletiva. Coordenadora de Formação de Recursos Humanos do Programa de Saúde da Universidade Federal de São Paulo no Parque Indígena do Xingu. sofia.mendonca@uol.com.br

* * * Professor Titular aposentado da Universidade Federal de São Paulo. Consultor Científico do Programa de Saúde dos Povos do Parque Indígena do Xingu. baruzzi@medprev.epm.br

${ }^{1}$ Agradecemos às mulheres Suyá (Kisêdjê) que participaram dos Encontros de Mulheres Xinguanas, relatando seus conhecimentos tradicionais sobre saúde reprodutiva. Agradecemos, também, aos colegas do Programa de Saúde da UNIFESP/EPM no Parque Indígena do Xingu, especialmente, Érica dos Santos Macedo, Evelyn Plácido dos Santos e Clayton de Carvalho Coelho, pela colaboracão no levantamento de campo nas aldeias Suyá, e à Natália da Silva Carvalho, aluna do sexto ano de medicina da UNIFESP, pelo levantamento de dados secundários e sua sistematização. A pesquisa recebeu recursos do Conselho Nacional de Desenvolvimento Científico e Tecnológico CNPq por meio de Bolsa de Produtividade de Pesquisa II concedida a Heloisa Pagliaro e de Iniciação Científica a Natália da Silva Carvalho, que trabalhou no levantamento e sistematização dos dados. importância na história desses povos e do país, surpreendendo antropólogos e demais estudiosos habituados à ideia do descenso demográfico secular e provável desaparecimento com a assimilação desses povos à sociedade nacional (Ribeiro, 1956, 1957; Gomes, 1991). As razões ou causas desse surpreendente evento são múltiplas e vêm sendo exploradas em muitas investigações levadas a efeito nas últimas décadas no campo da antropologia e da demografia indígena no Brasil. Cabe, no entanto, assinalar, neste espaço de discussão, por um lado, os fatores que, conjugados, foram fundamentais para que essas populações voltassem a crescer, e, por outro, registrar a crescente inquietação com os efeitos que eventualmente sejam gerados pelo crescimento e pelas mudanças na estrutura etária dessas populações.

A redução dos níveis de mortalidade, especialmente a infantil, contribuiu sobremaneira para o aumento da sobrevivência de recém-nascidos, jovens e adultos de muitas etnias, embora ainda permaneçam elevados. Esse fator, associado à manutenção ou à elevação dos níveis de fecundidade dessas populações, resultou em expressivo cres- 
cimento vegetativo, próximo de 3,5\% ao ano, em muitas etnias.

Como ocorre nessa fase do processo de transição demográfica, quando as populações, em geral, passam de decrescentes ou estáveis para populações em crescimento acelerado, assiste-se, no presente momento, a um rejuvenescimento importante das populações indígenas. Em muitos povos indígenas, a proporção de menores de 15 anos de idade supera a casa dos 50\%. Por outro lado, a melhoria das condições de saúde dessas populações tem propiciado o aumento da sobrevivência e repercutido na elevação da proporção dos maiores de 50 anos. Se a sobrevivência de adultos e idosos não tivesse acompanhado esse processo, o novo perfil demográfico representaria uma ameaça à preservação social e cultural dessas sociedades, cujas normas e valores são tradicionalmente transmitidos pelos velhos (Flowers, 1994). Na sociedade Suyá, por exemplo, o aumento da sobrevivência dos velhos tem concorrido para a recuperação de mitos e cerimônias há muito esquecidos.

Diferentes organizações sociais, sistemas familiares e de parentesco, regras de casamento e de residência, padrões de idade da menarca e da menopausa, casamento e nascimento do primeiro filho, normas relativas à concepção e contracepção, intervalo entre os nascimentos e tempo de aleitamento, entre tantos outros, são aspectos da cultura dos povos relativos à reprodução biológica e social que têm considerável influência nos regimes demográficos experimentados pelas diferentes sociedades, especialmente as de pequena escala. Sob o enfoque da relação entre sistemas culturais e comportamento reprodutivo, numerosos estudos de caso em demografia indígena foram realizados no Brasil (Pagliaro; Azevedo; Santos, 2005). Dentre muitos, destacam-se as pesquisas sobre os Mekranoti por Werner (1983), Yanomami do rio Mucajai de Early e Peters (1990), Guarani Mbyá de Parati por Lopez (2000), Xavánte de Pimentel Barbosa por Coimbra Jr, et al. (2002), Canela de Greene e Croker (1994), Bakairi de Picchi (1994), Tenetehara de Gomes (2002), Kamaiurá de Pagliaro e Junqueira (2007), povos do Alto Rio Negro de
Azevedo (2004), Kaiabi de Pagliaro (2005), Suruí de Arias et al. (2008).

Recente estudo sobre a dinâmica demográfica dos Suyá no período 1970-2004 (Pagliaro, et al., 2007) mostrou que o principal fator responsável pelo crescimento dessa população (3\% ao ano), que passou de 123 para 330 habitantes nesse período, foi a combinação entre altos níveis de natalidade e o declínio da mortalidade. Os níveis de natalidade atingiram 57,7 nascimentos por mil habitantes, e os de mortalidade geral 23,8 óbitos por mil habitantes. A estrutura etária da população se manteve jovem, sendo a população menor de 15 anos de idade próxima de $50 \%$ do total.

A suposição de que o processo de recuperação demográfica dos Suyá tenha sido gerado também por mudanças socioculturais, com repercussão em seu comportamento reprodutivo, incentivou a realização deste estudo, ${ }^{2}$ cujo objetivo é identificar alterações em seu padrão de fecundidade de 1970 a 2007, considerando os conhecimentos tradicionais de saúde reprodutiva e os aspectos da cultura e organização social desse povo, que intermediariam seu comportamento reprodutivo.

\section{PROCEDIMENTOS METODOLÓGICOS}

O estudo é do tipo descritivo de corte transversal ou de momento. Baseia-se principalmente em duas fontes de dados quantitativos: 1) registros de eventos demográficos e de saúde para o período 1970-2006; 2) levantamento de campo para o ano de 2007.

Os registros de eventos demográficos e de saúde foram extraídos dos arquivos do Programa de Saúde da Universidade Federal de São Paulo no Parque Indígena do Xingu, que possui um sistema de estatísticas vitais e migratórias contínuas, inédito no país, baseado em fichas médicas e livros de registro de eventos vitais dos habitantes do

2 Este estudo é um resultado parcial do Projeto Fecundidade e Saúde Reprodutiva das Mulheres Suyá desenvolvido pelos autores, no âmbito do programa de saúde, assistência, ensino e pesquisa que a Universidade Federal de São Paulo desenvolve desde 1965 no Parque Indígena do Xingu. 
Parque, alimentados regularmente desde a implantação do Programa em 1965.

As fichas médicas contêm, além das informações de saúde: número de registro do indivíduo no Programa de Saúde; fotos de identificação na infância, adolescência, idade adulta e velhice; etnia a que pertence; data de abertura da ficha; data de nascimento, estimada pela equipe médica que realizou o primeiro exame clínico dos indivíduos nascidos antes da implantação do Programa, e mês e ano para os nascidos a partir de 1965; os diferentes nomes que os indivíduos recebem durante o ciclo vital; sexo; data de óbito, local e causa de morte; nome dos pais e cônjuge(s); localidade ou aldeia de residência e deslocamentos espaciais; nome, sexo, data de nascimento e número de RG de saúde dos filhos. As fichas são arquivadas na seguinte ordem: etnias, aldeias, casas e famílias.

Nos livros de registro de eventos vitais estão registrados os indivíduos habitantes do Parque desde a criação do Programa de Saúde, compreendendo, até o presente, 43 anos sem interrupção. Esses livros contêm o número de RG do indivíduo no Programa de Saúde, nome, sexo, mês e ano de nascimento, etnia, números de registro e nomes dos pais, e, em caso de óbito, mês, ano e causa de morte.

Deve ser enfatizado que a existência de estatísticas vitais e migratórias contínuas para um longo período de tempo permitiu identificar os eventos demográficos ocorridos entre os Suyá de 1970 a 2006, e reconstruir as histórias reprodutivas das mulheres e a população por sexo e idade, para cada ano desse período. Para reconstruir a população, foi utilizado um Diagrama de Lexis, ${ }^{3}$ tendo por base a população Suyá cadastrada até 1970 $\left(\mathrm{p}_{1970}\right)$, por idades simples e sexo, à qual foram sendo acrescentados, ano a ano, até 2006, os nascimentos, óbitos, entradas e saídas das aldeias, nas idades em que esses eventos ocorreram.

\footnotetext{
${ }^{3} \mathrm{O}$ diagrama de Lexis é um gráfico formado por uma trama de linhas paralelas e diagonais, que representa, em duas dimensões, três variáveis demográficas: a data, a idade e o momento do nascimento, óbito ou qualquer idade e o momento do nascimento, óbito ou qualquer
outro evento demográfico, podendo, assim, representar
} a dinâmica de uma população (Welti, 1998).
Com os dados obtidos por meio dessa fonte de informações, foram estimados, por técnica direta, os indicadores clássicos de fecundidade atual ou de momento que possibilitaram identificar as diferenças de níveis e padrões etários da fecundidade e a sua variação no tempo, como taxas de fecundidade total (TFT), taxas de fecundidade específicas por idade (TEF), contribuição das mulheres menores de 30 anos para a fecundidade total, idade média e mediana de fecundidade, média de idade ao nascimento do primeiro filho e intervalo médio entre os nascimentos vivos (intergenésico).

O levantamento de dados mostrou que algumas mulheres tiveram a sua primeira gestação antes dos 15 anos, e nenhuma engravidou após os 44 anos de idade, o que conduziu à adaptação das medidas de fecundidade a esse padrão reprodutivo, contemplando as idades de 12 a 44 anos e não de 15 a 49 anos, como convencionado em estudos clássicos de fecundidade.

Para contornar as flutuações dos indicadores, resultantes do pequeno volume populacional, foram calculados indicadores médios para períodos de dez anos entre 1970 e 1999, e de seis anos de 2000 em diante, como tem sido usual em estudos de caso de populações indígenas no Brasil (Pagliaro, 2005).

A outra fonte de dados quantitativos foi o levantamento de campo realizado nas aldeias Suyá, em 2007, quando foram coletadas informações adicionais para completar as histórias reprodutivas das mulheres com idades entre 12 e 24 anos, tais como as idades da menarca e da primeira gestação. Com as informações obtidas nas duas fontes de dados (registro de eventos vitais e levantamento de campo), foram estimados, para 2007, indicadores de prolificidade e de sobrevivência dos filhos do total de mulheres e de mães, além das médias de gestações por mulher e por mãe. Para as mulheres de 12 a 24 anos, estimou-se a média de idade à menarca e à primeira gestação (interrompida ou não), e o intervalo médio entre a menarca e a primeira gestação.

Aspectos da cultura suyá relacionados a 
eventos, como gravidez, parto e puerpério, ao lado de regras de comportamento, que envolvem o ciclo reprodutivo das mulheres são baseados: a) na vivência dos autores com os Suyá; b) em relatos de mulheres, homens, agentes indígenas de saúde e professores dessa etnia, obtidos a partir dos módulos sobre esses temas do Curso de Agentes Indígenas de Saúde e, particularmente, nos III, IV e V Encontros de Mulheres Xinguanas ${ }^{4}$ realizados em 2006, 2007 e 2008 no Parque Indígena do Xingu; c) referências bibliográficas sobre os Suyá, com especial destaque para as de Antony Seeger, antropólogo que estuda os Suyá desde 1970.

\section{BREVES NOTAS SOBRE A HISTÓRIA E CULTURADOS SUYÁ}

Os Suyá ou Kisêdje, como se autodenominam, são um povo de língua Jê (ramo setentrional) com população de 400 pessoas em 2007, que habita o Parque Indígena do Xingu (PIX), na região Centro-Oeste do Brasil, onde vivem outros povos indígenas pertencentes às famílias linguísticas Aruak, Karib e Tupi, além dos Trumai, de língua isolada.

Os Suyá vivem em aldeias circulares, de acordo com o padrão tradicional Jê, com casas posicionadas em volta de uma praça aberta que abriga a casa dos homens. Atualmente, vivem em cinco localidades, uma aldeia maior, Ngôjwêre, onde se concentra a maior parte do povo Suyá, e nas pequenas aldeias Ngôsokô, Roptôtxi, Beira Rio e Wawi.

A sociedade Suyá é caracterizada por metades, classes e categorias de idades - períodos do ciclo vital por meio dos quais os Suyá marcam o tempo. Cada momento do ciclo de vida é nominado, sendo que os períodos de maior vulnerabilidade física e espiritual são: do nascimento até que a criança comece a andar; da puberdade; do nascimento de um filho; e da velhice, quando se torna avô ou avó, o que lhes confere uma mudança de status.

${ }^{4}$ Mendonça, S. Relatórios dos Encontros de Mulheres Xinguanas realizados em 2006, 2007 e 2008, Parque Indígena do Xingu, Projeto Xingu/UNIFESP, 2007 (mimeo).
A mudança de uma classe de idade para outra é marcada por ritos de passagem. Uma transição importante para os homens é a cerimônia de iniciação, que marca a saída da casa dos pais e a transferência para a casa dos homens, quando são treinados para a vida adulta. Após o nascimento do primeiro filho, que consuma o casamento, os homens se mudam para a casa da família da esposa, obedecendo à regra de residência que é matrilocal. Atualmente, nem todos os Suyá obedecem às regras de residência (Seeger, 1981).

As mulheres vivem na casa materna por toda a vida. Durante a puberdade e adolescência, são preparadas para a vida adulta pelas mulheres da casa, geralmente a mãe, as tias e avós. Conforme relatos das mulheres mais velhas e de agentes indígenas de saúde, a idade da primeira menstruação varia entre 12 e 14 anos. Quando o corpo da menina começa a se modificar e ela menstrua, passa a ser chamada de sumra-ndywy. Na ocasião, ela fica reclusa por aproximadamente dois meses, submete-se a rigorosa dieta alimentar e é proibida de ter relações sexuais. A obediência a essas regras visa ao bom desenvolvimento de seu corpo. Os interditos também incluem seus pais, por estarem envolvidos no processo de desenvolvimento dos filhos. A quebra das regras leva a punições; em geral, pode trazer doenças. Assim como entre povos alto-xinguanos, como os Kamaiurá, por exemplo, as adolescentes são escarificadas, lavam o corpo com ervas próprias, mantêm braços e tornozelos amarrados, procedimentos que visam ao amadurecimento para a vida adulta (Pagliaro; Junqueira neste volume).

Ainda conforme depoimentos das mulheres Suyá, antigamente, as atividades sexuais de homens e mulheres tinham início mais tarde do que hoje, pois "as mães cuidavam de suas filhas até o amadurecimento de seus corpos, e os rapazes aguardavam o término da reclusão pubertária. ${ }^{5}$ As mulheres Suyá também afirmam que o período de reclusão pubertária tem diminuído e que al-

5 Depoimento de mulher Suyá prestado durante o V En-
contro de Mulheres Xinguanas, no Parque Indígena do contro de Mul
Xingu, 2007. 
guns jovens têm se recusado a ficar reclusos. As mudanças são atribuídas às influências da mídia, sobretudo à televisão e à convivência, nas escolas, com jovens de outras etnias ou não-índios.

Após o nascimento do primeiro filho, as mulheres Suyá delimitam seu espaço, onde seu marido vem morar e constituir uma unidade doméstica. Elas são valorizadas pela sua capacidade de gerar filhos nos seus primeiros anos do ciclo produtivo, e sua autoridade aumenta à medida que têm mais filhos e que sua mãe envelhece. Na velhice, ainda se mantêm envolvidas nas atividades domésticas e familiares, sendo respeitadas por sua sabedoria e consultadas pelos mais jovens (Seeger, 1981).

Durante a gestação, as relações sexuais precisam ser frequentes - os Suyá acreditam que o feto se desenvolve pelo acúmulo do sêmem. O parto é frequentemente realizado pela mulher mais experiente da casa e, quando surgem complicações, recorre-se ao rezador ou a pessoas mais experientes de outras casas. A placenta é enterrada pela parteira. A criança é examinada e, se não possuir malformação, é entregue à mãe que amarra o cordão umbilical e a acolhe. Pegar um recém-nascidoé um importante ato social, pois indica aceitação da criança e responsabilidade por ela. Antigamente, os Suyá sacrificavam gêmeos, crianças com malformação, filhos de mulheres solteiras e de mães que haviam morrido no parto.

Conforme o sexo, a criança é pintada com urucum e tem os tornozelos, joelhos e braços amarrados com fibras de embira, para que cresça forte e saudável. Durante as suas primeiras semanas de vida, pai e mãe, com o auxílio da avó, assumem os seus cuidados.

Conforme relato das mulheres mais velhas, antigamente, no dia seguinte ao parto, o pai ia até a beira do rio, perfurava a glande do pênis com dente de cachorra, espécie de peixe muito frequente na região do Xingu, espremia o sangue, passava em seu corpo e voltava para casa. Esse procedimento representava a purificação do pai, impregnado pelo sangue da criança.

O nascimento é um importante momento de transição na vida dos pais. Dietas alimentares e regras de comportamento devem ser cumpridas pelo casal desde a gravidez até que a criança comece a andar, para garantir o seu bom desenvolvimento. A transgressão das regras pode comprometer a saúde física e espiritual da criança. A partir do nascimento, os pais são impedidos de ter relações sexuais até que a criança comece a andar. Se o pai for polígamo, deve abster-se também de relações sexuais com as outras esposas. Nos primeiros meses de vida da criança, os pais não devem exercer atividades que exijam força física, como esticar arco e flecha, derrubar roça, construir casa, fazer canoa, no que se refere ao pai; e trabalhar na roça, preparar alimentos e mexer com fogo, no tocante à mãe. Nesse período, é a avó ou uma irmã mais velha quem cuida da casa e do preparo dos alimentos. Outras pessoas que não estejam cumprindo as regras alimentares e de abstinência sexual são impedidas de carregar a criança, que pode ter a sua saúde física e espiritual prejudicada.

Vários procedimentos como massagens, amarrações, pinturas e banhos com ervas são realizados durante a primeira infância, para modelar e formar o corpo da criança, prevenir doenças e garantir a boa saúde. Para o bom desenvolvimento físico e espiritual da criança, a alimentação dos pais se restringe a peixes pequenos, carnes de caça, aves e alguns produtos da roça. Os Suyá acreditam que a transgressão das dietas alimentares por parte dos pais pode comprometer a saúde da criança, causar convulsões, provocar cansaço e febre.

As mulheres Suyá relatam não conhecer substância alguma para prevenir a gravidez e possuir um período de abstinência sexual pós-parto mais longo que as mulheres de outras etnias, o que lhes garante maior espaçamento entre os filhos.

O nome da criança é dado pelos avós na primeira semana de vida, sendo escolhido entre os nomes de antepassados. A escolha também depende das metades a que pertencem os pais. Atualmente, com o declínio da mortalidade e aumento da natalidade, faltam nomes, e com frequência algumas crianças demoram a recebê-los.

As mulheres mais velhas destacam que algumas práticas rituais e regras têm sido negligenciadas pelos jovens. Dentre as mudanças identificadas, 
incluem-se: a redução do período de reclusão pubertária de adolescentes de ambos os sexos; o recuo das idades ao casar, à primeira gestação e ao nascimento do primeiro filho; o desrespeito à regra de abstinência sexual desde o nascimento das crianças até que comecem a andar; a transgressão da dieta alimentar, com a incorporação de "alimentos do branco", que não estão incluídos nas proibições; a falta de interesse das jovens em aprender a "fazer parto"; o recurso a profissionais de saúde do distrito e não a rezadores, quando há complicações no parto; a preferência por dar à luz em hospitais das cidades do entorno do Parque. Os Suyá deixaram também de cumprir regras tradicionais que previam o sacrifício de gêmeos, crianças com malformação, filhos de mulheres solteiras e de mães que haviam morrido no parto. A desobediência a regras sociais tradicionais foi uma das principais contribuições para o aumento da fecundidade e, conforme o depoimento das mulheres, um dos fatores mais importantes que explicam o grande número de doenças das crianças atualmente, entre as quais a desnutrição infantil.

\section{TENDÊNCIAS DA FECUNDIDADE DO PERÍO- DO 1970-2006}

\section{Indicadores de momento}

A evolução dos níveis de fecundidade das mulheres Suyá pode ser observada por meio das

Fonte de dados brutos: Projeto Xingu, DMP/UNIFESP
Taxas de Fecundidade Total (TFT), ${ }^{5}$ estimadas para quatro períodos entre 1970 e 2006 (Tabela 1).

Entre as décadas de 1970 e 1990, a TFT das mulheres Suyá aumentou de 5,2 para 8,0 filhos nascidos vivos, em média, por mulher, declinando para 6,7 filhos em 2000-2006.

As taxas específicas de fecundidade por idades (TEF) permitem compreender as mudanças ocorridas no padrão etário da fecundidade. Essas taxas mostram que, na década de 1970, a estrutura da fecundidade identificava-se com o padrão tardio, com maior concentração entre as mulheres dos grupos etários 30-34 e 35-39 anos (Gráfico 1). A partir da década de 1980, os níveis de fecundidade das mulheres com 15-19 e 20-24 anos se elevaram, principalmente os desse segundo grupo etário, e a estrutura da fecundidade adquiriu um padrão mais jovem. Essas características são mais evidentes na década de 1990, quando há um importante aumento da fecundidade das mulheres das faixas etárias 12-14, 15-19 e 20-24 anos, além dos grupos de 35-39 e 40-44 anos. No período 2000-06, os níveis de fecundidade voltaram a declinar em quase todas as idades, exceto nos grupos de 25-29 e 30-34anos.

A distribuição proporcional das taxas específicas de fecundidade nos diversos períodos analisados (Gráfico 2) mostra que houve aumento da participação das mulheres mais jovens na fecundidade, mas que a contribuição das mulheres com 30 e mais anos continuou elevada. Em razão dos altos níveis da fecundidade total, a dis-

Tabela 1 - Indicadores de Fecundidade das Mulheres Suyá (PIX), 1970-2006

\begin{tabular}{|c|c|c|c|c|}
\hline Indicadores & 1970-79 & 1980-89 & 1990-99 & $2000-06$ \\
\hline Taxas de fecundidade total (TFT) das mulheres de 12 a 44 anos & 5,2 & 5,8 & 8,0 & 6,7 \\
\hline Contribuição das mulheres $<30$ anos para a fecundidade total & 63,0 & 64,6 & 62,8 & 61,0 \\
\hline Idade média de fecundidade (em anos) & 25,6 & 25,9 & 25,3 & 25,3 \\
\hline Idade mediana à fecundidade (em anos) & 27,0 & 24,0 & 24,5 & 24,0 \\
\hline Média de idade ao nascimento do $1^{\circ}$ filho (em anos) & 19,2 & 18,3 & 16,3 & 17,5 \\
\hline Intervalo médio entre os nascimentos (em meses) & 49,0 & 45,0 & 36,4 & 37,5 \\
\hline
\end{tabular}

${ }^{6}$ TFT - indicador demográfico de momento, que mede o nível ou a intensidade da fecundidade e representa o número médio de filhos por mulher durante seu período reprodutivo. 
Gráfico 1- Taxas específicas de fecundidade das mulheres Suyá de 1970 a 2006, por períodos

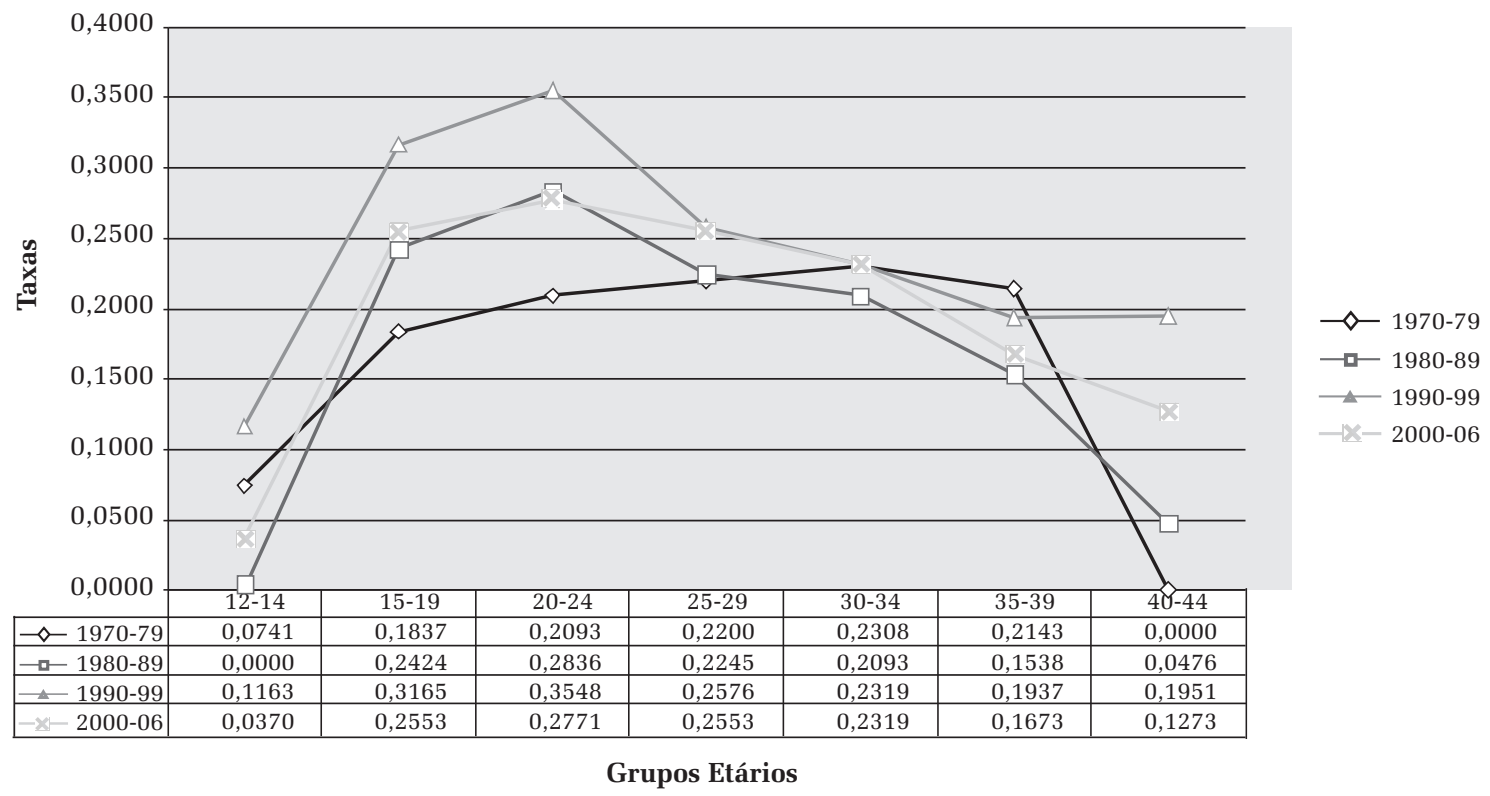

Gráfico 2 - Distribuição proporcional das taxas específicas de fecundidade das mulheres Suyá de 1970 a 2006, por períodos

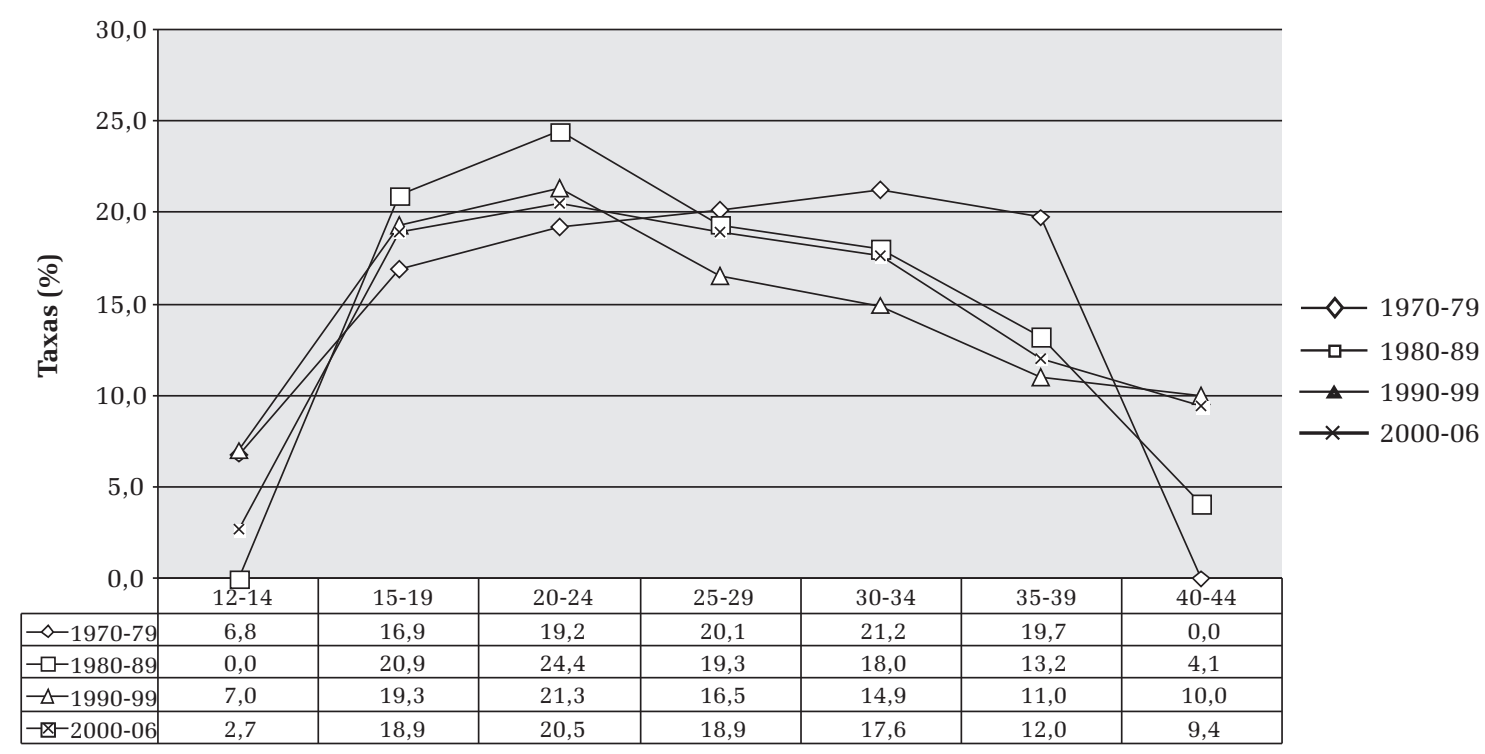

Grupos Etários

tribuição da fecundidade ainda se mantém dispersa nos diferentes grupos etários, tendendo a uma maior concentração nas idades menores (15-19 e 20-24 anos).

O padrão etário da fecundidade dessas mulheres estaria em transição entre o padrão “tar- dio” e o “jovem” com concentração nas idades de 20 a 24 anos e a contribuição das mulheres menores de 30 anos de idade variando entre 61 e 64,6\% da fecundidade total (Tabela 1).

A evolução da fecundidade para um padrão mais jovem, com polarização no grupo de 20-24 
anos, reflete na redução da idade mediana de fecundidade, de 27 anos na década de 1970, para aproximadamente 24 anos a partir da década de 1980. A persistência de altos níveis de fecundidade entre as mulheres de 30 e mais anos manteve constante a idade média de fecundidade, em todos os períodos, em torno dos 25 anos. As médias de idade ao nascimento do primeiro filho declinaram de 19,2 anos, na década de 1970, para 16,3 anos na década de 1990, voltando a aumentar no período 2000-06 (17,5 anos). O intervalo médio entre os nascimentos diminuiu de 49 para 36,4 meses entre $1970-79$ e 1990-99 e aumentou para 37,5 meses em 2000-06 (Tabela 1).

\section{HISTÓRIAS REPRODUTIVAS}

\section{Indicadores de fecundidade acumulada}

No ano de 2007, 91 mulheres de 15 ou mais anos de idade viviam nas aldeias Suyá, sendo 68 Suyá, e 23 pertencentes a outras etnias habitantes do PIX, casadas com homens Suyá. A reconstrução das histórias reprodutivas dessas mulheres, com informações sobre o número de gestações, de mulheres prolíficas, de nascimentos vivos, de filhos mortos, sobreviventes, natimortos e de abortos até $\mathrm{o}$ ano de 2007 pode ser observada na Tabela 2 . Do total de mulheres, $10 \%$ permaneciam solteiras e nunca tinham engravidado, sendo: quatro por grupos de idade, em 2007 (números absolutos) com idades entre 15 e 19 anos; duas de 25 a 29 anos; três de 30 ou mais anos. Destaca-se o subregistro de natimortos (2) e o número relativamente elevado de abortos registrados (50), o que poderia representar uma frequência de 0,64 abortos por mulher que alguma vez engravidou. A mais elevada frequência de abortos foi registrada entre as mulheres de 35-39 anos ( 1 aborto, em média, por mulher) seguida das mulheres do grupo 20-24 anos $(0,9)$.

A média de gestações do total de mulheres foi de 4,3 por mulher (Tabela 3). Nas idades de 1519 anos e 20-24 anos, as médias de gestações foram de 1,2 e 3,7 por mulher, respectivamente, e, entre as mulheres com fecundidade completa (4549 anos), de 7,4 por mulher (Tabela 3).

As médias de nascimentos vivos e de filhos sobreviventes do total de mulheres de 15 e mais anos foram, respectivamente, de 3,7 e 3,4 filhos por mulher (Tabela 3). A diferença de 0,3 filhos entre essas médias seria atribuída aos óbitos de filhos nascidos vivos dessas mulheres. Entre as mulheres de 20 e 24 anos, essa diferença é de 0,1 filhos, ao passo que, no grupo 45-49 anos, que representa a fecundidade completa ou parturição final das mulheres, a diferença é de 0,8 filhos.

As diferenças entre as médias de gestações e de nascimentos vivos por mulher se devem à mortalidade intrauterina espontânea e induzida, $\mathrm{e}$ à natimortalidade. Para o total de mulheres de $15 \mathrm{e}$ mais anos, a diferença entre a média de gestações

Tabela 2 - Histórias reprodutivas das mulheres de 15 anos e mais, moradoras das aldeias Suyá (PIX),

\begin{tabular}{|c|c|c|c|c|c|c|c|c|}
\hline $\begin{array}{l}\text { Grupos de } \\
\text { idades }\end{array}$ & Mulheres & Gestações & $\begin{array}{l}\text { Mulheres que } \\
\text { engravidaram }\end{array}$ & $\begin{array}{l}\text { Nascimen- } \\
\text { tos vivos }\end{array}$ & $\begin{array}{c}\text { Filhos } \\
\text { sobreviventes }\end{array}$ & $\begin{array}{l}\text { Filhos } \\
\text { mortos }\end{array}$ & Natimortos & Abortos \\
\hline 15 a 19 & 19 & 23 & 15 & 12 & 12 & - & - & 9 \\
\hline 20 a 24 & 14 & 52 & 14 & 39 & 38 & 1 & 1 & 12 \\
\hline 25 a 29 & 14 & 50 & 12 & 44 & 37 & 3 & - & 6 \\
\hline 30 a 34 & 4 & 16 & 3 & 14 & 14 & - & - & 2 \\
\hline 35 a 39 & 7 & 46 & 7 & 38 & 37 & 1 & 1 & 7 \\
\hline 40 a 44 & 9 & 59 & 8 & 57 & 53 & 4 & - & 2 \\
\hline 45 a 49 & 7 & 52 & 7 & 47 & 41 & 6 & - & 5 \\
\hline $50 \mathrm{e}+$ & 17 & 95 & 16 & 88 & 79 & 9 & _ & 7 \\
\hline 15 a 50 e + & 91 & 393 & 82 & 339 & 311 & 24 & 2 & 50 \\
\hline
\end{tabular}

Fonte: Levantamento de campo em 2007 e arquivos do Projeto Xingu, DMP/UNIFESP 
Tabela 3 - Indicadores do comportamento reprodutivo das mulheres de 15 anos e mais, moradoras das aldeias Suyá (PIX) por grupos de idades, em 2007

\begin{tabular}{l|c|c|c|c}
\hline $\begin{array}{l}\text { Grupos de } \\
\text { idades }\end{array}$ & $\begin{array}{c}\text { Média de gestaçóes } \\
\text { por mulheres }\end{array}$ & $\begin{array}{c}\text { Média de gestaçóes por } \\
\text { mulheres que } \\
\text { engravidou }\end{array}$ & $\begin{array}{c}\text { Média de nascimentos } \\
\text { vivos por mulher }\end{array}$ & $\begin{array}{c}\text { Média de filhos } \\
\text { sobreviventes por } \\
\text { mulher }\end{array}$ \\
\hline 15 a 19 & 1,2 & 1,5 & 0,6 & 0,6 \\
\hline 20 a 24 & 3,7 & 3,7 & 2,8 & 2,7 \\
\hline 25 a 29 & 3,6 & 4,2 & 3,1 & 2,6 \\
\hline 30 a 34 & 4,0 & 5,3 & 3,5 & 3,5 \\
\hline 35 a 39 & 6,6 & 6,6 & 5,4 & 5,3 \\
\hline 40 a 44 & 6,6 & 7,4 & 6,3 & 5,9 \\
\hline 45 a 49 & 7,4 & 7,4 & 6,7 & 5,9 \\
\hline 50 e + & 5,6 & 5,9 & 5,2 & 4,7 \\
\hline 15 a 50 e & 4,3 & 4,8 & 3,7 & 3,4 \\
\hline
\end{tabular}

Fonte: Levantamento de campo em 2007 e arquivos do Projeto Xingu, DMP/UNIFESP

$(4,3)$ e de filhos nascidos vivos $(3,7)$ por mulher foi de 0,6 .

O período reprodutivo das Suyá geralmente tem início entre os 11 e 13 anos de idade e termina antes dos 44 anos. Dentre as 23 jovens com idades de 12 a 14 anos, em 2007, a média de idade à menarca foi de 11,3 anos, sendo que duas ainda não tinham menstruado, e cinco não souberam informar a idade em que menstruaram pela primeira vez. Para as mulheres de 15-19 anos $(\mathrm{N}=19)$ e de 20-24 anos ( $\mathrm{N}=14)$, a média de idade à menarca foi de 12,1 anos. O intervalo médio entre a menarca e a primeira gestação foi de 2,7 anos para as mulheres de 15 a 24 anos. Ressalta-se que $21 \%$ das jovens de 15 a 19 anos, até 2007, nunca tinham engravidado.

O término do período reprodutivo das Suyá fica entre os 35-39 anos. Essa estimativa baseia-se na média de idade de 38 anos estimada ao nascimento do último filho das mulheres com fecundidade completa no período 2000-07.

\section{DISCUSSÃO DOS RESULTADOS E CONSIDE- RAÇÕES FINAIS}

Assim como verificado para outros povos indígenas no Brasil (Pagliaro; Azevedo; Santos, 2005) e na América Latina (McSweeney; Arps, 2005), os Suyá também têm vivenciado um processo de recuperação demográfica, resultante da combinação de altos níveis de natalidade e do descenso contínuo da mortalidade desde a década de 1970 (Pagliaro, et al., 2007). Entre 1970 e 2004, a população Suyá cresceu em média 3\% ao ano.

O presente artigo apresentou as tendências de níveis e padrões etários da fecundidade das mulheres Suyá, no período 1970-2007, além de descrever os conhecimentos tradicionais e regras culturais relacionados ao seu comportamento reprodutivo. A pesquisa utilizou dados de levantamento de campo em 2007 e de estatísticas vitais contínuas de um período de quase 40 anos, o que é raro em estudos de demografia indígena, geralmente baseados em informações fragmentadas ou focadas em curtos períodos de tempo. A volatilidade dos indicadores, causada pelo pequeno volume da população, foi suavizada pelo emprego de séries temporais de longo período de tempo.

Os primeiros achados da pesquisa apontam para o aumento da fecundidade das mulheres Suyá entre as décadas 1970 e 1990, de 5,2 filhos para 8 filhos nascidos vivos, em média, por mulher, com tendência de declínio no período 20002006 (6,7 filhos).

Os níveis de fecundidade encontrados entre as Suyá são tão expressivos quanto os estimados para outros povos indígenas, habitantes da região Amazônica, como verificado para os Kaiabi (Pagliaro, 2005), Mekranotire (Werner, 1983), Xavante de Pimentel Barbosa e de Sangradouro Volta Grande (Coimbra Jr, et al., 2002; Souza; Santos, 2001), al- 
guns povos habitantes da região do Alto Rio Negro (Azevedo, 2004), Sateré-Mawé (Teixeira, 2005), Yanomami do Rio Mucajai (Early; Peters, 1990). A fecundidade das Suyá é também muito próxima da estimada para as mulheres autodeclaradas indígenas no Censo Demográfico de 2000, residentes de áreas rurais da região Centro-Oeste do Brasil, de 7,2 filhos por mulher (IBGE, 2005; Wong; Morell; Carvalho, 2006). Entretanto, a fecundidade das Suyá, representa mais do que o triplo do nível de fecundidade do conjunto da população brasileira, de 2,4 filhos, em 2000 (IBGE, 2004).

Os níveis de fecundidade das mulheres Suyá estariam associados a padrões reprodutivos caracterizados por curtos intervalos de tempo entre os nascimentos, de aproximadamente 40 meses, em média; ao aleitamento prolongado, de 12 ou mais meses; ao longo período de abstinência sexual pós-parto, de aproximadamente doze meses; às médias de idade ao nascimento do primeiro filho, com variações entre 16,3 e 17,5 anos, a partir de 1990, como verificado para outros povos indígenas no Brasil (Early; Peters, 1990; Pagliaro; Junqueira, 2007; Souza; Santos, 2005).

A estrutura da fecundidade por idade das Suyá seria semelhante àquela verificada para os Kaiabi (Pagliaro, 2005), entre os quais as mulheres com menos de 30 anos de idade contribuem com cerca de $60 \%$ da fecundidade total. Para as mulheres autodeclaradas indígenas no Censo de 2000 , residentes nas áreas rurais do país, a contribuição das mulheres menores de 30 anos de idade para o nível de fecundidade é de aproximadamente 77\% (Wong, et al., 2006).

No tocante aos limites de idade do período reprodutivo, constatou-se, no levantamento de campo realizado em 2007, com mulheres de 12 a 24 anos, que a primeira menstruação ocorre entre os 11,3 e 12,1 anos. A idade média à menopausa foi de 38 anos. Early e Peters (1990) estimaram a média de idade à menarca das Yanomami do Rio Mucajai em 12,4 anos. Os autores destacam que, embora outros fatores possam estar envolvidos, a idade precoce à menarca estaria relacionada à alimentação saudável dos Yanomami, baseada em produtos da agricultura, caça e pesca, como a dos Suyá.

O intervalo entre a menarca e a primeira gestação das Suyá foi de 2,7 anos para as mulheres de 15 a 24 anos. A média de gestações por mulher do grupo 45-49 anos, idade em que já completaram o período reprodutivo, foi de 7,4 gestações, sendo de 6,7 a média de filhos nascidos vivos.

As mudanças verificadas no comportamento reprodutivo das Suyá, como o aumento dos níveis de fecundidade a partir dos anos 80 e a maior intensidade da fecundidade das mulheres de 15 a 24 anos, estariam em consonância com o que foi relatado pelas Suyá mais velhas. Elas afirmaram desconhecer ervas medicinais de efeito contraceptivo, que seriam do conhecimento de outros povos indígenas, como por exemplo, os povos do Alto Xingu (Junqueira, 1978; Pagliaro; Junqueira, 2007). As Suyá relataram ainda que os contatos com a sociedade envolvente interferiram na sua tradição cultural de forma significativa, tendo inclusive influído na prática de sacrifício de crianças indesejáveis ou com malformação, também usual no passado entre os povos do Alto Xingu (Junqueira, 1978) e os Yanomami do Rio Mucajai (Early; Peters, 1990), assim como entre outros povos indígenas no Brasil. O longo período de abstinência sexual pós-parto, a amamentação prolongada e o aborto seriam os recursos utilizados pelas Suyá, no presente, para regular os nascimentos. O contato com a sociedade envolvente estaria repercutindo também no sentido de modificar o comportamento dos jovens suyá, que hoje se casam e iniciam o período reprodutivo mais cedo do que no passado, além de transgredirem as regras alimentares e de abstinência sexual pós-parto. A transgressão das regras socioculturais tradicionais seria, conforme o relato das mulheres Suyá, um dos fatores associados ao aumento da fecundidade, especialmente nas mulheres jovens. Um dos exemplos citados em relação ao aumento do número de filhos seria a falta de nomes de antepassados disponíveis atualmente para nomear as crianças, que hoje são em maior número.

Lopez (2000) também observou que dificul- 
dades de controle social no grupo Guarani Mbyá de Paraty (RJ) levaram a modificações em seu comportamento reprodutivo. Conforme a autora, a média de idade à menarca diminuiu de 14 para 12,7 anos; os casamentos estão se realizando mais cedo (14,9 anos) do que antigamente (20 anos); a média de idade à primeira gestação declinou de 17,7 para 15,6 anos.

Os padrões reprodutivos encontrados emergem da organização social dos Suyá, que valoriza a capacidade de as mulheres gerarem filhos e lhes confere maior autoridade perante a sociedade na medida em que têm mais filhos. Uma prole numerosa lhes dá direito a um status de maior respeito, assim como ao homem. Ao envelhecer, o grande número de netos é também importante para que mulheres e homens mantenham uma posição de destaque na esfera social. Os casamentos apenas se consumam com a geração de filhos; a abstinência sexual pós-parto, o aleitamento prolongado e as interrupções das gestações são os meios para evitar o nascimento das crianças não-desejadas, dado que os Suyá não usam ervas contraceptivas como outros povos indígenas (Junqueira, 2002; Pagliaro; Junqueira 2007).

A ampliação do tamanho de família dos Suyá estaria refletindo, por um lado, a melhoria das condições de saúde e a queda da mortalidade, decorrente das ações médico-sanitárias levadas a efeito a partir de 1965 no Xingu, garantindo o aumento da sobrevivência não só de recém-nascidos, mas de toda a população. A redução dos níveis de mortalidade estaria contribuindo também para: 1) aumentar a possibilidade de as mulheres mais velhas levarem suas gestações a termo; 2) aumentar a estabilidade das uniões conjugais, que, no passado recente, eram frequentemente interrompidas pela morte de um dos cônjuges; 3) possibilitar um melhor equilíbrio entre os sexos na população (razão de sexos), criando mais opções de uniões conjugais, principalmente entre pessoas mais velhas e viúvas, por exemplo.

Por outro lado, o aumento do tamanho das famílias seria também o reflexo das mudanças socioculturais apontadas pelas velhas Suyá, de desrespeito às práticas tradicionais de controle da natalidade, como a abstinência sexual no pós-parto e o sacrifício de gêmeos, crianças não-desejadas e com malformação. O casamento precoce e a redução do intervalo entre os nascimentos justificariam também, conforme a observação dessas mulheres, a incidência de novas doenças entre as crianças, principalmente a desnutrição.

(Recebido para publicação em julho de 2009) (Aceito em setembro de 2009)

\section{REFERÊNCIAS}

ARIAS, M.M.V., SANTOS, R.V., COIMBRA JR., C.E.A. Aspectos culturales de la reproducción: el caso de los Suruí de Rondônia y Mato Grosso, Brasil. Investidación y Educación en Enfermeria, Medellín, v.26, n.1, p.86-97, 2008 .

AZEVEDO, M.M. Demografia dos povos indígenas do Alto Rio Negro/Amazonas: um estudo de caso de nupcialidade e reprodução. 2004. Tese (Doutorado em Demografia) Programa de Pós-Graduação em Ciências Sociais do Instituto de Filosofia e Ciências Humanas, da UNICAMP. Campinas, SP, 2004.

Os censos demográficos e os "índios": dificuldades para reconhecer e contar. In: RICARDO, C.A (Org.) Povos indígenas no Brasil 1996/2000. São Paulo: Instituto Socioambiental, 2000. p.79-83.

BARUZZI, R.G. Do Araguaia ao Xingu. In:

JUNQUEIRA, C. (Org.) Parque Indígena do Xingu. Saúde, cultura e história. São Paulo: Terra Virgem, 2005. p.59112.

CAMARGO, C.P.F; JUNQUEIRA, C.; PAGLIARO, H. Reflexões acerca do mundo cultural e do comportamento reprodutivo dos Kamaiurá ontem e hoje. In: PAGLIARO, H.; AZEVEDO, M.M.; SANTOS, R.V., (Org.) Demografia dos povos indígenas no Brasil. Rio de Janeiro: FIOCRUZ/ ABEP, 2005. p.119-134.

COIMBRA JR, C.E.A.; FLOWERS, N.; SALZANO, F.M.; SANTOS, R.V. The Xavánte in transition. Health, ecology, and bioanthropology in Central Brazil. Ann Arbor: University of Michigan Press, 2002. 344 p.

EARLY, J.D.; PETERS, J.F. The population dynamics of the Mucajai Yanomama. New York: Academic Press, 1990. $152 \mathrm{p}$.

FLOWERS, N.M. Crise e recuperação demográfica: os Xavánte de Pimentel Barbosa, Mato Grosso. In: SANTOS, R.V.; COIMBRA JR., C.E.A. (Org.) Saúde dos povos indígenas. Rio de Janeiro: Fiocruz, 1994. p.213-242.

GOMES, M. P. Os índios e o Brasil: ensaio sobre um holocausto e sobre uma nova possibilidade de convivência. Petrópolis: Vozes, 1991. 238 p.

O índio na história. O povo Tenetehara em busca da liberdade. Petrópolis: Vozes, 2002. 631 p.

GREENE, M. E.; CROCKER, W. H. Some demografic aspects of the Canela indians of Brazil. South American Indian Studies, Nova York: Bennington College, n.4, p.4762, 1994. 
IBGE. Tendências demográficas. Uma análise dos resultados da amostra do censo demográfico 2000. Rio de Janeiro: 2004. 155 p. (Coleção estudos \& pesquisas,13).

Uma análise dos indígenas com base nos resultados da amostra dos censos demográficos de 1991 e 2000. Rio de Janeiro: IBGE, 2005. 152p.

JUNQUEIRA, C. Os indios do Ipavu. Um estudo sobre a vida do grupo Kamaiurá. São Paulo: Ática, 1978. 111 p.

Sexo e desigualdade entre os Kamaiurá e os Cin-

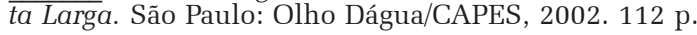

LOPEZ, G.M.A. A fecundidade entre os Guarani: um legado de Kunhankarai. 2000. 217f. Tese (Doutorado em Saúde Pública) - Programa de Pós-Graduação da Escola Nacional de Saúde Pública, Fundação Oswaldo Cruz. Rio de Janeiro, 2000.

McSWEENEY, K.; ARPS, S. A Demographic Turnaround The Rapid Growth of Indigenous Populations in Lowland Latin America. Latin American Research Review, Austin, v.18, n.1, fev., 2005

MELATTI, J. C. População indígena. Brasília: UNB, 2004 (Série Antropologia, 345)

PAGLIARO, H. A revolução demográfica dos povos indígenas no Brasil: a experiência dos Kaiabi do Parque Indígena do Xingu, Mato Grosso, Brasil - 1970-1999, 2002 197 f. Tese (Doutorado em Saúde Pública) - Programa de Pós-Graduação em Saúde Pública da Universidade de São Paulo. 2002.

A revolução demográfica dos povos indígenas: a experiência dos Kaiabi do Parque Indígena do Xingu, Mato Grosso. In: ___ AZEVEDO, M.M.; SANTOS, R.V. (Org.) Demografia dos povos indígenas no Brasil. Rio de Janeiro: Editora Fiocruz/Abep, 2005. p.79-102.

; JUNQUEIRA, C. Recuperação demográfica e fecundidade dos Kamaiurá, povo Tupi do Parque Indígena do Xingu, Brasil Central, 1970-2003. Saúde e Sociedade, São Paulo, v.16, n.2, p.37-47, 2007.

; CARVALHO, N.S.; RODRIGUES, D.; BARUZZI, R.G. Dinâmica demográfica dos Suyá, povo Jê do Parque Indígena do Xingu, Brasil Central, 1970-2004. Cadernos de Saúde Pública, Rio de Janeiro, v.23, n.5,p.1071-1081, 2007.

AZEVEDO, M.M. SANTOS, R.V. Demografia dos povos indígenas no Brasil: um panorama critico. In: indígen ; ; (Org.). Demografia dos povos p.11-32.
PICCHI, D. Observations about a Central Brazilian indigenous population: the Bakairi. South American Indian Studies, New York, Bennington College, v.4, p.3746, 1994.

RIBEIRO, D. Convívio e contaminação. Efeitos dissociativos da depopulação provocada por epidemias em grupos indígenas. Sociologia, São Paulo, v.18, n.1, p.3-50, 1956.

Culturas e línguas indígenas do Brasil. EducaÇão e Ciências Sociais, Rio de Janeiro, v.2, n.6, p.4-102, 1957.

RODRIGUES, D. A UNIFESP: Escola Paulista de Medicina, o Projeto Xingu e a política de atenção a saúde dos povos indígenas no Brasil. In: BARUZZI, R.G.; JUNQUEIRA, C. (Org.). Parque Indígena do Xingu. Saúde, cultura e história. São Paulo: Terra Virgem, 2005. p.259273 .

SEEGER, A . Nature and society in Central Brasil. The Suyá indians of Mato Grosso. Cambridge: Harvard University Press; 1981.

SOUZA, L. G.; SANTOS, R. V. Perfil demográfico da população indígena Xavánte de Sangradouro: Volta Grande, Mato Grosso (1993-1997), Brasil. Cadernos de Saúde Pública, Rio de Janeiro, v.17, n.2, p.355-366, 2001.

TEIXEIRA, P.; BRASIL, M. Estudo demográfico dos Sateré-Mawe': um exemplo de censo participativo. In PAGLIARO, H; AZEVEDO, M.M.; SANTOS, R.V. (Org.) Demografia dos povos indígenas no Brasil. Rio de Janeiro: Ed. Fiocruz/Abep; 2005. p.135-154.

UNIFESP/EPM. Relatório. In: ENCONTRO DE MULHERES XINGUANAS, 4 realizado no Pólo Base Wawi, Parque Indígena do Xingu, 2007. São Paulo: 2007. (mimeo).

WERNER, D. Fertility and pacification among the Mekranoti of Central Brazil. Human Ecology, New York, v.11, n.2, p.227-245, 1983.

WONG, L.R.; MORELL, M.G. de; CARVALHO, R.L. de. Notas sobre o comportamento reprodutivo dos povos indígenas no período 1991-2000. In: ENCONTRO NACIONAL DE ESTUDOS POPULACIONAIS, 15, 2006. Caxambu. Anais...: Caxambu: ABEP, 2006 $<$ www.abep.org.br $>$.

WELTI, C. Demografia II. México: Prolap/Unam; 1998. 


\section{FERTILITY AND REPRODUCTIVE HEALTH OF WOMEN Suya (Kisêdjê): demographic and cultural}

\section{Heloisa Pagliaro \\ Sofia Mendonça, \\ Roberto Baruzzi}

Since 1970, the Suyá, an Indigenous people, inhabitants of the Xingu Indigenous Park (MT), has been experiencing a demographic recovery, as well as it has been happening with other Brazilian Indigenous peoples. Recent studies analyse the reasons that have led to a reversion of the long depopulation process undergone by Indigenous peoples in Brasil. The conjecture that the Suyá's demographic recovery was due to social and cultural changes that reflected in their reproductive behavior was the reason for this study that describes their fertility levels and patterns between 1970 and 2007. Data is based on continuous vital statistics and field research. Results analysis is grounded on their sociocultural system and historical knowledge of the Suyá's reproductive health.

KEY wORDS: Suyá, Indigenous demography, fertility of Indigenous women, Brasil’s s Indigenous peoples.
FÉCONDITÉ ET LA SANTÉ REPRODUCTIVE

DES FEMMES SUYA (Kisêdjê): caractéristiques démographiques et culturelles

\section{Heloisa Pagliaro \\ Sofia Mendonça \\ Roberto Baruzzi}

Ainsi que d'autres groupes indigènes au Brésil, les Suyá, peuple qui habite le Parc Indigène du Xingu (MT), ont inicié un processus de récupération démographique depuis les anneés de 1970. Les raisons qui mènent à la reversion du processus de depeuplement des groupes indigènes au Brésil sont discutés dans plusieurs travaux scientifiques recents. La suposition que la récuperation démographique des Suyá soit menné par des changements culturels qui repercutent sur leur comportemment reproductif justifie la realisation du présent étude. L' article analise les niveaux et standarts de leur fécondité de 1970 jusqu' à 2007. Les donnés proviennent des statistiques vitales et de recherche sur le terrain. La discussion des resultats s'appui sur des informations de leur sistème socioculturel et des connaissances traditionnels sur leur santé reproductive.

Mots-Clés: Suyá, démographie indigene, fécondité de femmes indigenes, peoples indigenes du Brésil.

Heloísa Pagliaro - Doutora em Saúde Pública pela Universidade de São Paulo. Cientista social, mestre em Demografia pelo Instituto de Demografia da Universidade de Paris I. Lotada no Centro de Recursos Humanos da UFBA e está em exercício no Departamento de Medicina Preventiva da Universidade Federal de São Paulo, onde desenvolve pesquisa demográfica junto a povos indígenas, no âmbito do Programa de Saúde dos Povos do Parque Indígena do Xingu - Projeto Xingu. Bolsista de Produtividade de Pesquisa II do CNPq e integra o GT Demografia dos Povos Indígenas da Associação Brasileira de Estudos Populacionais. Além de artigos em periódicos nacionais e internacionais e capítulos em livros, publicou "Demografia dos Povos Indígenas no Brasil" (2005).

Sofia Mendonça - médica sanitarista, mestre em Antropologia pela Universidade Católica de São Paulo e doutoranda em Saúde Coletiva na Universidade Federal de São Paulo. É Coordenadora de Formação de Recursos Humanos do Programa de Saúde da Universidade Federal de São Paulo no Parque Indígena do Xingu desde 1991. Foi coordenadora da Comissão Intersetorial de Saúde Indígena do Conselho Nacional de Saúde, de 1995 a 1999. Publicou vários artigos científicos e capítulos de livros sobre o tema saúde indígena e a formação de recursos humanos.

Roberto G. Baruzzi - Médico, com curso de Medicina Tropical no Instituto de Medicina de Antuérpia, na Bélgica e de Epidemiologia e Estatística Médica na London School of Hygiene and Tropical Medecine Epidemiolology and Medical Statistics. Deu início ao Programa de Saúde dos Povos do Parque Indígena do Xingu, Projeto Xingu, que coordenou até 1996, quando se aposentou como Professor Titular do Departamento de Medicina Preventiva da Universidade Federal de São Paulo (UNIFESP/EPM) e passou a atuar como Consultor Científico do Projeto. Além de artigos em periódicos nacionais e internacionais, capítulos em livros e livros, publicou "Parque Indígena do Xingu. História, Saúde e Cultura” (2005). 
